\title{
ANALISIS KEBUTUHAN PENGEMBANGAN SDM BIDANG BINA MARGA DINAS PUPR PROVINSI NTB
}

\author{
Dewi Utary1, Agusdin2, Hermanto3
}

\author{
1 Master of Management Program, Mataram University, Indonesia \\ E-mail: miracleskm@gmail.com \\ 2 Faculty of Economics and Business, Mataram University, Indonesia. \\ 3 Faculty of Economics and Business, Mataram University, Indonesia.
}

\begin{tabular}{l}
\hline ARTICLE INFO \\
\hline Keywords: \\
Workload, Human Resource Needs, \\
Workload Indicators of Staffing Need \\
(WISN), Needs Assesement. \\
Beban Kerja, Kebutuhan Sumber Daya \\
Manusia, Workload Indicators of \\
Staffing Need. (WISN), Needs \\
Assesement. \\
How to cite: \\
Utary, Dewi.,Agusdin., Hermanto \\
(2018). Analisis Kebutuhan \\
Pengembangan SDM Bidang Bina Dinas \\
PUPR Provinsi NTB . \\
JMM UNRAM, 7(2),36-49 \\
DOI: \\
10.29303/jmm.v7i2.316
\end{tabular}

\section{ABSTRACT}

This study aims to analyze the workload of each work unit and the category of human resources (HR), analyze the number and HR competencies of each work unit and to analyze the types of human resource development needed by the Highways Department of the Public Works and Spatial Planning (PUPR) West Nusa Tenggara Province (NTB). The population in this study were all employees who worked on the Highways Sector of the PUPR Provincial Office of NTB Province which numbered 49 people. The population in this study were all employees working in the Highways Division of the Public Works Department of West Nusa Tenggara Province with documentation techniques, questionnaires, in-depth interviews and Focus Group Discussion (FGD) as the data collection methods used. The data analysis technique used in this study is WISN (Workload Indicators of Staffing Need). The results showed that the workload for each unit in the Highways Sector of the PUPR Office of NTB Province was still not optimal, there were a shortage of human resources of 34 people consisting of 24 (twenty four) technical personnel and 10 (ten) non-technical personnel, as well as still need HR development to improve HR competencies.

Penelitian ini bertujuan untuk menganalisis beban kerja masing-masing unit kerja dan kategori sumber daya manusia (SDM), menganalisis kebutuhan jumlah dan kompetensi SDM masing-masing unit kerja dan untuk menganalisis jenis pengembangan SDM yang 


\section{PENDAHULUAN}

Perencanaan sumber daya manusia (SDM) terdiri dari estimasi permintaan terhadap SDM daya dimasa mendatang, baik dalam kuantitas maupun kualitasnya, membandingkan antara permintaan yang diharapkan dengan SDM yang tersedia saat ini, serta menentukan kekurangan atau kelebihan jumlah SDM berdasarkan strategi dan tujuan organisasi. Masalah sumber daya manusia mengandung berbagai upaya pengembangan dan pemberdayaan sumber daya manusia dalam suatu organisasi. Upaya tersebut meliputi upaya perencanaan, pengadaan, pendayagunaan, serta pembinaan dan pengawasan mutu sumber daya manusia untuk mendukung penyelenggaraan pembangunan nasional (Peraturan Pemerintah No. 64, 2012). Perencanaan sumber daya manusia (human resources planning) adalah kegiatan menghimpun dan menggunakan informasi untuk menunjang keputusan investasi sumber daya dalam berbagai aktivitas sumber daya manusia (SDM). Tahapan dalam melakukan perencanaan SDM meliputi kegiatan analisis permintaan SDM, analisis ketersediaan atau suplai SDM dan rekonsiliasi antara permintaan dan suplai SDM yang tersedia (Simamora, 2006), dari hasil analisis tersebut dapat diketahui perkiraan kebutuhan, ketersediaan dan perbandingan antara kebutuhan dan ketersediaan SDM yang ada, sehingga dapat dibuat alternatif tindakan sesuai dengan hasil perbandingan yang ada, misalnya melakukan perekrutan, membatasi pengangkatan pegawai baru, promosi, pengembangan dan pelatihan dan lain-lain. Perencanaan SDM dilakukan dengan menyesuaikan kebutuhan pembangunan, baik lokal, nasional maupun global. Salah satu metode yang dapat dipakai untuk menghitung beban kerja dan mengestimasi jumlah kebutuhan SDM adalah dengan metode Workload Indicators of Staffing Need (WISN). Metode ini akurat dipakai untuk menghitung kebutuhan SDM berdasarkan pada beban pekerjaan nyata yang dilaksanakan oleh setiap kategori SDM pada tiap unit kerja pada 
Bidang Bina Marga Dinas Pekerjaan Umum dan Penataan Ruang (PUPR) Provinsi Nusa Tenggara Barat (NTB). Hasil WISN menggambarkan permasalahan perencanaan SDM dari segi beban kerja, jumlah kebutuhan tenaga dan distribusinya. Salah satu komponen yang tidak kalah penting adalah kompetensi tenaga. Dalam menganalisis hasil WISN komponen ini erat kaitannya dengan pengembangan SDM. Untuk membuat perencanaan pengembangan SDM diperlukan data jenis pengembangan yang dibutuhkan, data ini dapat diperoleh melalui analisis kebutuhan pengembangan (needs analysis). Analisis kebutuhan pengembangan SDM dapat dilakukan melalui pendekatan analisis organisasi (organizational analysis) yang menilai unit atau bagian dari organisasi yang memerlukan pengembangan, analisis tugas (task/job analysis) yang mengidentifikasi pekerjaan atau skill apa yang harus dipelajari, dan analisis orang (person analysis) yang membantu memilih siapa orang yang akan dikembangkan (Simamora, 2006).

Berdasarkan latar belakang tersebut di atas, maka dapat diidentifikasikan permasalahan sebagai berikut:

1. Terjadi kekosongan sejumlah jabatan karena pejabat yang pensiun, meninggal dunia, dan yang dipinjam atau dipindah tugaskan ke bagian dan instansi lain.

2. Terdapat beberapa karyawan dan pejabat melakukan tugas rangkap.

3. Terdapat ketidakseimbangan beban kerja yaitu kelebihan jumlah dan kompetensi (overstaffed) kategori SDM berlatar belakang pendidikan non teknik dan kekurangan jumlah dan kompetensi (understaffed) kategori SDM berlatar belakang pendidikan teknis dan non teknis pada unit kerja Seksi Perencanaan Teknis Jalan, Seksi Pembangunan Jalan, dan Seksi

Tujuan Penelitian adalah:

1. Menganalisis beban kerja masing-masing unit kerja dan kategori SDM pada Bidang Bina Marga Dinas PUPR Provinsi NTB.

2. Menganalisis kebutuhan jumlah dan kompetensi SDM masing-masing unit kerja pada Bidang Bina Marga Dinas PUPR Provinsi NTB.

3. Menganalisis jenis pengembangan SDM yang dibutuhkan Bidang Bina Marga Dinas PUPR Provinsi NTB

\section{TINJAUAN LITERATUR}

Hasil penelitian terdahuhu yang dijadikan rujukan didapatkan berbagai hasil yang berbeda. Penelitian yang dilakukan oleh Fitriah (2016) yang mengukur beban kerja dengan metode WISN, menunjukkan masih tingginya beban kerja tenaga kesehatan pada Rumah Sakit Ernaldi Bahar di Sumatera Selatan. Hasil yang berbeda ditemukan dalam penelitian lainnya, Das (2013) menemukan bahwa beban kerja tenaga kesehatan rendah sehingga terjadi overload atau underutilization tenaga pada ruang kebidanan perguruan tinggi kedokteran Kolkata, India.Penelitian lainnya menemukan bahwa metode WISN tidak hanya dapat digunakan untuk mengukur beban kerja dan menghitung kebutuhan tenaga, tetapi juga dapat digunakan untuk membuat perencanaan kebutuhan rekruitmen program baru dengan membuat standarisasi beban kerja. Penelitian lain juga menemukan bahwa belum ada perencanaan untuk pengembangan, pemeliharaan dan peningkatan karir staf pada suatu organisasi. Penelitian yang dilakukan oleh Benhard (2015) menemukan bahwa belum ada persamaan persepsi antara Dinas Kesehatan dengan Puskesmas di Kabupaten Minahasa 
dalam hal metode dan alat ukur perencanaan SDM, sehingga belum ada perencanaan untuk pengembangan, pemeliharaan dan peningkatan karir staf. Penelitian Abdideh (2014) menghasilkan standar kebutuhan dokter keluarga untuk program pelayanan dokter keluarga berdasarkan populasi di Iran. Beberapa penelitian terdahulu yang jadikan rujukan mengindikasikan tingginya kebutuhan pengembangan SDM bagi organisasi dalam meningkatkan kinerja karyawan, salah satunya adalah penelitian yang dilakukan Mile, Mekel dan Karuntu (2014) yang menemukan bahwa pelaksanaan pelatihan dan pengembangan karyawan berpengaruh atau memiliki dampak terhadap peningkatan kinerja perusahaan di PT. Pegadaian Gorontalo Utara, dimana manajemen perusahaan mengambil manfaat terutama dalam melakukan perencanaan karir karyawan dalam jangka panjang. Penelitian yang dilakukan oleh Wicaksono (2016) menunjukkan bahwa diperlukan pengembangan SDM dalam bentuk pelatihan dalam bidang pengadaan, pengembangan, pemberian kompensasi, pengintegrasian, pemeliharaan dan pelepasan sumber daya manusia bagi karyawan SKM (Sigaret Kretek Mesin) Unit. V PT. Gudang Garam, Tbk. untuk meningkatkan kemampuan dan keahliannya secara optimal. Beberapa perbedaan yang ditemukan dalam penelitian-penelitian tersebut menggambarkan beragam permasalahan yang terkait dengan SDM yang dapat diidentifikasi dengan melakukan pengukuran beban kerja menggunakan metode WISN. Penelitian ini akan menggunakan metode WISN untuk mengukur beban kerja dan kebutuhan SDM di masing-masing unit pada Bidang Bina Marga Dinas PUPR Provinsi NTB, yang kemudian dianalisis kebutuhan pengembangannya.

\subsection{Perencanaan Sumber Daya Manusia}

Perencanaan kebutuhan SDM selama ini masih bersifat administratif kepegawaian dan belum dikelola secara professional, belum sesuai dengan kebutuhan organisasi dan kebutuhan nyata di lapangan, serta belum berorientasi jangka panjang. Seperti penelitian yang dilakukan Benhard,dkk. (2015) yang menemukan belum adanya persamaan persepsi antara Dinas Kesehatan dengan Puskesmas dalam hal alat ukur dan metode perencanaan SDM. Perencanaan SDM pada Bidang Bina Marga Dinas PUPR Provinsi NTB diharapkan berorientasi pada Rencana Pembangunan Jangka Panjang yang disusun oleh pemerintah Provinsi NTB. Perencanaan SDM merupakan proses yang secara sistematis mengkaji keadaan, sumber daya manusia untuk memastikan bahwa jenis, jumlah, dengan kompetensi yang tepat akan tersedia pada saat mereka dibutuhkan.

\subsection{Analisis Beban Kerja}

Menurut Wideman (2002) dalam Hardjawinata (2006) mendefinisikan beban kerja adalah jumlah unit kerja yang ditugaskan pada satu sumber daya dalam periode waktu tertentu. Kebutuhan ini akan berkembang menyesuaikan dengan tuntutan dan perkembangan organisasi sehingga perlu dilakukan penilaian tiap tahunnya. Berbagai metode yang telah dikembangkan dapat dijadikan patokan dalam melakukan analisis beban kerja. Metode yang paling akurat untuk peramalan jangka pendek saat ini adalah dengan menghitung beban kerja (workload) yang merupakan analisis pekerjaan terhadap beban kerja yang perlu disesuaikan (Simamora, 2006). Workload Indicators of Staffing Need (WISN) merupakan sebuah standar pengukuran kebutuhan tenaga berdasarkan indikator beban kerja yang pertama kali di ujicobakan sekitar tahun 1998. Metode WISN adalah alat manajemen sumber daya yang menghitung kebutuhan staf berdasarkan beban kerja untuk kategori staf tertentu. Metode WISN memiliki kelebihan yaitu mudah digunakan baik secara teknis, 


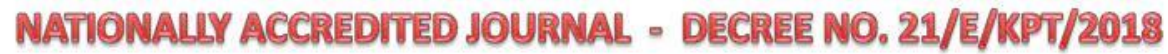

komprehensif, realistis serta memberikan kemudahan dalam menentukan variasi kebutuhan SDM dalam berbagai tipe organisasi.

Menurut Shipp (1998), langkah untuk menghitung tenaga berdasarkan WISN ada 5 langkah yaitu:

1. Menetapkan waktu kerja tersedia (WKT)

Tujuannya untuk menentukan waktu kerja efektif selama satu tahun, untuk masing-masing kategori SDM yang akan kita hitung.

Rumusnya : Waktu kerja tersedia $=\{A-(B+C+D+E)\} X F$

Keterangan:

A = Jumlah hari kerja yang mungkin dalam setahun

$\mathrm{B}=$ Cuti tahunan

$\mathrm{C}=$ Pendidikan dan pelatihan

$\mathrm{D}=$ Hari libur nasional

$\mathrm{E}=$ Ketidakhadiran kerja (rata-rata ketidakhadiran kerja selama satu tahun karena alasan sakit, tidak masuk kerja dengan atau tanpa alasan)

$\mathrm{F}=$ Waktu kerja (waktu kerja dalam satu hari)

2. Menentukan unit kerja dan kategori SDM yang dihitung

Bertujuan menetapkan unit kerja dan kategori SDM yang bertanggung jawab memberikan kinerja sesuai tugas pokok dan fungsinya masing-masing yang telah ditetapkan oleh organisasi. Informasi ini bisa didapatkan dari:

a. Data pegawai berdasarkan pendidikan yang bekerja pada tiap unit kerja

b. Peraturan perundangan yang berkaitan dengan jabatan fungsional SDM

c. Standar kompetensi dan uraian jabatan pada tiap unit kerja yang ada

3. Menyusun standar beban kerja

Merupakan volume atau kuantitas beban kerja selama 1 tahun per kategori SDM. Standar beban kerja untuk satu kegiatan pokok dihitung berdasarkan waktu rata-rata yang dibutuhkan untuk menyelesaikan kegitan tersebut dan waktu kerja yang tersedia.

Rumusnya: $\quad$ Standar beban kerja $=\frac{\text { Waktu kerja tersedia }}{\text { Rata-rata waktu per kegiatan pokok }}$

Data yang diperlukan antara lain:

a. Waktu yang tersedia

b. Bagan struktur organisasi

c. Kegiatan pokok (kegiatan pokok dan uraian kegiatan, serta tanggung jawab masingmasing kategori SDM)

d. Rata-rata waktu untuk menyelesaikan jenis kegiatan pokok

e. Standar profesi

f. Menetapkan waktu berdasarkan kesepakatan

4. Menyusun standar kelonggaran dan faktor kelonggaran 
Bertujuan memperoleh faktor-faktor kelonggaran setiap kategori SDM meliputi jenis kegiatan dan waktu penyelesaian suatu kegiatan yang tidak terkait langsung dengan pelayanan pasien. Pengamatannya meliputi:

a. Kegiatan-kegiatan yang tidak terkait langsung dengan pelayanan pasien

b. Frekuensi tiap kegiatan dalam satuan hari, minggu dan bulan

c. Waktu rata-rata yang dibutuhkan untuk menyelesaikan kegiatan tersebut Rumusnya:

Standar kelonggaran $=\frac{\text { Rata-rata waktu per faktor kelonggaran }}{\text { Waktu yang tersedia }}$

Faktor Kelonggaran Kategori (FKK) digunakan sebagai pengali dalam penentuan jumlah keseluruhan SDM yang dibutuhkan pada langkah WISN berikutnya. FKK dihitung dengan cara sebagai berikut:

1. Mengubah Standar Kelonggaran Kategori dari setiap kegiatan penunjang yang penting menjadi persentase waktu kerja.

2. Menjumlahkan semua Standar Kelonggaran Kategori tersebut

3. Menggunakan rumus matematik untuk mendapatkan FKK, sebagai berikut:

FKK $=1$ dibagi dengan $\{1$ dikurangi (Total SKK yang dibagi 100) $\}$

Faktor Kelonggaran Individu (FKI) memperhitungkan waktu kerja yang digunakan beberapa kategori tenaga dalam setiap kategori tenaga untuk kegiatan-kegiatan tambahan. FKI menghitung berapa petugas yang dibutuhkan untuk melakukan kegiatan-kegiatan ini secara "setara purna waktu" (whole time equivalent, WTE). FKI ditambahkan dalam perhitungan akhir dari keseluruhan kebutuhan staf. Perhitungannya sebagi berikut:

1. Mengalikan masing-masing Standar Kelonggaran Individu dengan jumlah orang yang melakukan kegiatan tersebut,

2. Menjumlahkan semua hasil yang diperoleh diatas, kemudian membagi hasil tersebut dengan Waktu Kerja Tersedia (WKT).

Apabila jumlah tenaga yang melaksanakan suatu kegiatan bervariasi antar kegiatan, maka perlu dilakukan perhitungan tersendiri atas masing-masing kelompok kegiatan yang dikerjakan oleh jumlah tenaga yang sama, dan kemudian menjumlahkannya.

5. Menghitung kebutuhan tenaga per unit kerja

Bertujuan memperoleh jumlah dan kategori SDM yang dibutuhkan untuk menyelenggarakan tugas pokok dan upaya pengembangan dalam kurun waktu satu tahun (Depkes, 2004). Rumusnya :

Kuantitas kegiatan pokok

Kebutuhan tenaga $=$ Standar beban kerja 


\section{Jurnal Magister Manajemen Unram}

Hasil perhitungan kebutuhan tenaga setiap kegiatan pokok kemudian dikalikan dengan FKK dan ditambahkan dengan FKI, untuk mendapatkan jumlah kebutuhan tenaga secara keseluruhan. Data yang diperlukan:

a. Waktu yang tersedia

b. Standar beban kerja

c. Standar kelonggaran

d. Kuantitas kegiatan pokok tiap unit kerja selama 1 tahun

Penelitian yang menggunakan metode WISN dalam mengukur beban kerja telah banyak dilakukan antara lain oleh Fitriah (2016), Govule dkk. (2015), Awadh (2015), Satish dkk. (2015), Abideh dkk. (2014), Dharmayuda (2014) dan Das dkk. (2013) . Penelitian-penelitian tersebut dilakukan pada berbagai kategori SDM yang berbeda. Beberapa penelitian mendapatkan hasil beban kerja yang tinggi pada kategori SDM yang diteliti, namun ada pula yang menemukan beban kerja rendah sehingga terjadi overload tenaga.

\subsection{Pengembangan Sumber Daya Manusia}

Pengembangan SDM membantu para karyawan mempersiapkan diri menghadapi perubahan di pekerjaan mereka yang dapat diakibatkan oleh teknologi baru, desain pekerjaan, pelanggan baru atau pasar produk baru (Simamora, 2006). Pada tahap awal organisasi perlu melakukan fase penilaian yang ditandai dengan kegiatan analisis kebutuhan pelatihan (training need analysis). Analisis kebutuhan pengembangan SDM dapat dilakukan melalui pendekatan analisis organisasi (organizational analysis) yang menilai unit atau bagian dari organisasi yang memerlukan pengembangan, analisis tugas (task/job analysis) yang mengidentifikasi pekerjaan atau skill apa yang harus dipelajari, dan analisis orang (person analysis) yang membantu memilih siapa orang yang akan dikembangkan (Simamora, 2006). Untuk menentukan secara tepat kebutuhan pengembangan SDM diperlukan tiga analisis (Mangkunegara, 2003:53-54; Simamora, 2006) yaitu:

1. Organizational analysisA

nalisis organisasi adalah suatu analisis yang dilakukan dengan tujuan untuk menjawab pertanyaan tentang bagian mana dari organisasi yang harus dikembangkan. Analisis organisasi mencoba menjawab dimana sebaiknya dilakukan titik berat pelatihan di dalam perusahaan dan faktor apa yang dapat mempengaruhi pelatihan.

2. Job/task analysis (Analisis pekerjaan/jabatan)

Analisis tugas adalah suatu analisis yang dilakukan dengan tujuan untuk menjawab pertanyaan tentang apa yang harus dipelajari para peserta agar dapat melaksanakan tugas secara efektif. Berikut langkah-langkah dalam analisis jabatan:

a. Mengkaji organisasi secara keseluruhan dan kesesuaian tiap jabatan;

b. Menentukan bagaiamana informasi analisis jabatan akan digunakan;

c. Pemilih jabatan-jabatan yang akan dianalisis;

d. Mengumpulkan data dengan teknik analisis jabatan tertentu;

e. Menyiapkan uraian jabatan;

f. Menyiapkan spesifikasi jabatan.

3. Person analysis

Analisis orang adalah suatu analisis dengan tujuan untuk menjawab pertanyaan tentang siapa yang harus dikembangkan. Sumber datanya dapat berupa :
a. Job Description;
b. Performance Standar;
c. Performance evaluation;
d. Observasi kerja. 


\section{Jurnal Magister Manajemen Unram}

Pelatihan-pelatihan yang akan diberikan pada SDM yang ada pada Bidang Bina Marga Dinas PUPR Provinsi NTB adalah pelatihan untuk mengikuti standar kompetensi jabatan dan juga pelatihan bersertifikasi yang telah pernah diikuti oleh SDM yang ada tetapi masa berlaku sertifikatnya telah berakhir.

\section{METODE PENELITIAN}

Penelitian ini merupakan penelitian deskriptif dengan pendekatan kuantitatif dan kualitatif. Penelitian deskriptif merupakan penelitian dengan tujuan untuk membuat deskripsi, gambaran, atau lukisan secara sistematis, faktual dan akurat mengenai fakta-fakta, sifat serta hubungan antar fenomena yang diselidiki (Nazir, 2003). Pada penelitian ini digambarkan hasil analisis perencanaan SDM pada Bidang Bina Marga Dinas PUPR Provinsi NTB dengan mengestimasi jumlah kebutuhan SDM dan kebutuhan pengembangannya. Pendekatan kuantitatif digunakan untuk menghitung beban kerja dan kebutuhan SDM dengan metode WISN. Data kualitatif digunakan dalam melakukan analisis kebutuhan pengembangan SDM melalui analisis kebutuhan organisasi, analisis kebutuhan pekerjaan dan analisis kebutuhan personal.

Langkah-langkah yang dilakukan adalah:

1. Menganalisis beban kerja setiap unit kerja dan kategori SDM serta menghitung jumlah kebutuhan dan kompetensi SDM dengan menggunakan metode WISN.

2. Metode analisis kualitatif pada penelitian ini dilakukan dengan mengeksplorasi kebutuhan pengembangan SDM dengan menggunakan analisis kebutuhan organisasi (organizational analysis), analisis kebutuhan pekerjaan (job/task analysis), dan analisis kebutuhan personal (person analysis) yang didapatkan dari informasi yang diberikan informan melalui wawancara.

a. Analisis Kebutuhan Organisasi (organizational analysis)

Pada penelitian ini analisis organisasi bertujuan mengidentifikasi analisis kebutuhan pelatihan pada Bidang Bina Marga Dinas PUPR Provinsi NTB, untuk melihat kesesuaian kebutuhan pelatihan pada tiap individu dengan kebutuhan organisasi dan hasil organisasi juga digunakan untuk menentukan prioritas terhadap kebutuhan pelatihan yang akan dibutuhkan. Peningkatan kompetensi SDM dapat dilakukan salah satunya dengan dilaksanakannya pelatihan.

b. Analisis kebutuhan pekerjaan (job/task analysis)

Analisis ini merupakan dasar bagi pengembangan program pelatihan yang dimaksudkan untuk membantu pegawai meningkatkan pengetahuan, skill, dan sikap terhadap suatu pekerjaan. Adapun langkah-langkah dalam melakukan analisis pekerjaan/jabatan menurut Ivancevich (2007) adalah:

1. Mengkaji organisasi secara keseluruhan dan kesesuaian tiap jabatan;

2. Menentukan bagaiamana informasi analisis jabatan akan digunakan;

3. Pemilih jabatan-jabatan yang akan dianalisis;

4. Mengumpulkan data dengan teknik analisis jabatan tertentu;

5. Menyiapkan uraian jabatan;

6. Menyiapkan spesifikasi jabatan

c. Analisis kebutuhan personal (person analysis)

Analisis individu bertujuan untuk memeriksa seberapa baik individu karyawan dalam melaksanakan pekerjaannya, dengan melakukan analisis individu akan didadapatkan kebutuhan pelatihan yang diperlukan oleh karyawan sehingga dapat diupayakan program pelatihan yang dapat menanggulangi masalah tersebut. 


\section{Jurnal Magister Manajemen Unram $\quad$ Vol. 7, No 2. Juni 2018 NATIONALY ACCREDITED JOURNAL - DECREE NO. 21/E/KPT/2018}

\section{HASIL PENELITIAN DAN PEMBAHASAN}

\subsection{Karakteristik Responden}

Karakteristik umur responden pada Bidang Bina Marga Dinas PUPR Provinsi NTB didominasi oleh umur yang yang relatif tidak muda lagi yang berumur 40-49 tahun sebesar 44,9\%, dan yang berumur 50-59 tahun sebesar 42,86 \%, hal ini terjadi karena pada beberapa tahun terakhir tidak ada kebijakan pengangkatan aparatur sipil negara oleh pemerintah pusat. Karakteristik jenis kelamin responden sebagian besar berjenis kelamin laki-laki yaitu sebesar 71,4\%. Komposisi kategori SDM yang ada di Bidang Bina Marga Dinas PUPR Provinsi NTB sebagian besar diisi oleh tenaga teknis, dimana kategori tersebut didominasi oleh SDM berjenis kelamin laki-laki. Sebagai contoh, babatan pengawas jalan dan jembatan, serta jabatan pengelola pengawasan yang berada dibawah Seksi Pembangunan Jalan seluruhnya diisi oleh SDM dengan jenis kelamin laki-laki. SDM yang ada pada Bidang Bina Marga Dinas PUPR Provinsi NTB didominasi oleh SDM berpendidikan SMA/yang sederajat yaitu sebesar 51,02\%, hal ini terjadi karena standar kompetensi yang disyaratkan oleh Dinas PUPR Provinsi NTB untuk beberapa kategori staf baik tenis maupun non teknis yang adalah minimal setingkat SMA/sederajat sehingga menyebabkan distribusi latar belakang pendidikan tenaga yang dominan ada pada Bidang Bina Marga Dinas PUPR Provinsi NTB adalah SMA/sederajat. Sebagian besar SDM pada Bidang Bina Marga Dinas PUPR Provinsi NTB memiliki masa kerja 11-15 tahun yaitu sebesar 69,4\%. Sebagian besar responden memiliki status kepegawaian sebagai PNS yaitu sebesar 93,9\%, sedangkan responden dengan status kepegawaian non PNS berjumlah 3 orang atau 6,1\%. Sebagian besar responden pada Bina Marga Dinas PUPR Provinsi NTB adalah tipe staf teknis yaitu sebesar 59,2\%, hal ini disebabkan oleh karena beberapa kategori SDM yang ada pada Bidang Bina Marga mempunyai standar kompetensi jabatan untuk diisi oleh staf yang berlatar belakang teknis.

\subsection{Kategori Sumber Daya Manusia}

Bidang Bina Marga Dinas PUPR Provinsi NTB memiliki 13 kategori tenaga yang meliputi jabatan Kepala Bidang, Kepala Seksi, Pejabat Pembuat Komitmen (PPK), Penyusun Rencana Program, Pengelola Data Administrasi dan Verifikasi, Verifikator Keuangan, Pengadministrasi Umum, Pengelola Pengawasan, Pengawas Jalan dan Jembatan, Pengelola Sosialisasi dan Layanan Informasi, Pengelola Sosialisasi dan Layanan Informasi, Pengemudi, dan Caraka.

\subsection{Unit Kerja}

Jumlah unit kerja yang ada pada Bidang Bina Marga Dinas PUPR Provinsi NTB berjumlah 3 unit, terdiri atas, Seksi Perencanaan Teknis Jalan, Seksi Pembangunan Jalan, dan Seksi Pembinaan Teknis Jalan. Masing-masing unit kerja terdiri atas beberapa kategori tenaga.

\subsection{Waktu Kerja Tersedia (WKT)}

Unsur-unsur yang harus diperhatikan dalam menghitung WKT adalah: hari kerja pertahun, cuti tahunan, pendidikan dan pelatihan, libur nasional, ketidakhadiran karena sakit, ijin, atau keperluan lainnya, dan waktu bekerja setiap kategori tenaga setiap harinya. Berdasarkan hal tersebut rata-rata WKT yang dimiliki kategori tenaga yang ada pada Bidang Bina Marga Dinas PUPR Provinsi NTB pada tahun 2018 adalah 1374 jam/tahun. 


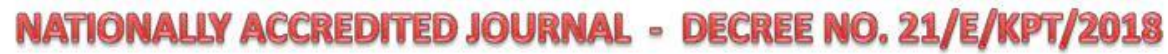

\subsection{Beban Kerja dan Kebutuhan SDM}

Tabel 1. Kebutuhan dan Rasio WISN Setiap Kategori SDM Bidang Bina Marga Dinas PUPR

Provinsi NTB

\begin{tabular}{|c|c|c|c|c|}
\hline No. & Unit Kerja & $\begin{array}{l}\text { Kategori SDM dalam Unit } \\
\text { Kerja }\end{array}$ & $\begin{array}{l}\text { Tipe } \\
\text { SDM }\end{array}$ & $\begin{array}{c}\text { Jumlah } \\
\text { Kekurangan }\end{array}$ \\
\hline \multirow[t]{4}{*}{1.} & \multirow{4}{*}{$\begin{array}{l}\text { Seksi } \\
\text { Perencanaan } \\
\text { Teknis Jalan }\end{array}$} & PPK Perencanaan & Teknis & 1 \\
\hline & & Pengelola Keuangan & $\begin{array}{l}\text { Non } \\
\text { Teknis }\end{array}$ & 1 \\
\hline & & $\begin{array}{l}\text { Pengelola Data } \\
\text { Administrasi dan Verifikasi }\end{array}$ & $\begin{array}{l}\text { Non } \\
\text { Teknis }\end{array}$ & 2 \\
\hline & & Caraka & $\begin{array}{l}\text { Non } \\
\text { Teknis }\end{array}$ & 1 \\
\hline \multirow[t]{6}{*}{2.} & \multirow{6}{*}{$\begin{array}{l}\text { Seksi } \\
\text { Pembanguna } \\
\text { n Jalan }\end{array}$} & PPK Pembangunan & Teknis & 3 \\
\hline & & $\begin{array}{l}\text { Pengawas Jalan dan } \\
\text { Jembatan }\end{array}$ & Teknis & 5 \\
\hline & & Pengelola Pengawasan & Teknis & 6 \\
\hline & & Pengadministrasi Umum & $\begin{array}{l}\text { Non } \\
\text { Teknis }\end{array}$ & 1 \\
\hline & & $\begin{array}{l}\text { Pengelola Data } \\
\text { Administrasi dan Verifikasi }\end{array}$ & $\begin{array}{l}\text { Non } \\
\text { Teknis }\end{array}$ & 2 \\
\hline & & Pengemudi & $\begin{array}{l}\text { Non } \\
\text { Teknis }\end{array}$ & 5 \\
\hline \multirow[t]{6}{*}{3.} & \multirow{6}{*}{$\begin{array}{l}\text { Seksi } \\
\text { Pembinaan } \\
\text { Teknik Jalan }\end{array}$} & $\begin{array}{l}\text { Pengelola Sosialisasi dan } \\
\text { Layanan Informasi }\end{array}$ & Teknis & 1 \\
\hline & & $\begin{array}{l}\text { Pengelola Monitoring dan } \\
\text { Evaluasi }\end{array}$ & \begin{tabular}{|l|} 
Non \\
Teknis \\
\end{tabular} & 1 \\
\hline & & $\begin{array}{l}\text { Pengelola Data } \\
\text { Administrasi dan Verifikasi }\end{array}$ & $\begin{array}{l}\text { Non } \\
\text { Teknis }\end{array}$ & 2 \\
\hline & & Pengemudi & $\begin{array}{l}\text { Non } \\
\text { Teknis }\end{array}$ & 1 \\
\hline & & Caraka & $\begin{array}{l}\text { Non } \\
\text { Teknis }\end{array}$ & 1 \\
\hline & & & Jumlah & 33 \\
\hline
\end{tabular}

Sumber: Data primer diolah, 2018

Berdasarkan tabel 1. diatas tampak bahwa pada Bidang Bina Marga Dinas PUPR Provinsi NTB terdapat unit-unit yang mengalami beban kerja tinggi (rasio WISN<1) dan membutuhkan tambahan tenaga adalah Seksi Perencanaan Teknis Jalan dengan kategori Kepala Seksi, PPK Perencanaan, Pengelola Data Administrasi dan Verifikasi, Pengelola Keuangan, dan Caraka. Kemudian pada Seksi Pembangunan Jalan dengan kategori PPK Pembangunan, Pengawas Jalan dan Jembatan, Pengelola Pengawasan, Pengelola Data Administrasi dan Verifikasi, Pengadministrasi Umum, dan Pengemudi. Selanjutnya pada Seksi Pembinaan Teknik Jalan dengan kategori Pengelola Data Administrasi dan Verifikasi, Pengelola Monitoring dan Evaluasi, Pengelola Sosialisasi dan Layanan Informasi, Pengemudi, dan Caraka. 
Beberapa unit sudah memiliki tenaga yang sesuai dengan beban kerjanya (rasio WISN=1) yaitu Bidang Bina marga dengan kategori Kepala Bidang, Seksi perencanaan Teknis Jalan dengan kategori Pengadministrasi Umum, Penyusun Rencana Program, dan Pengemudi. Seksi Pembangunan Jalan sudah memiliki tenaga dengan rasio yang sesuai dengan beban kerjanya (rasio WISN=1) dengan kategori Kepala Seksi Pembangunan Jalan dan Pengadministrasi Umum, selanjutnya Seksi Pembinaan Teknik Jalan dengan kategori Kepala Seksi Pembinaan Teknik Jalan, Pengadministrasi Umum, serta Penyusun Rencana Program. Pada masing-masing unit yang ada pada Bidang Bina Marga Dinas PUPR Provinsi NTB tidak ada yang memiliki beban kerja rendah (rasio WISN>1). Hasil analisis menunjukkan terdapat beberapa kategori tenaga yang masih merangkap tugas pada unit yang sama ataupun berbeda dalam waktu bersamaan dengan tugastugas tambahan yang bersifat administratif maupun teknis. Menurut WHO (2010) dalam menganalisis hasil WISN harus diperhatikan faktor-faktor yang mempengaruhi beban kerja tinggi seperti: jumlah SDM yang kurang, komposisi pekerjaan yang tidak proporsional, atau kompetensi tenaga yang ditempatkan di unit kerja suatu organisasi tidak sesuai standar. Penelitian yang dilakukan oleh Philip Govule dkk.(2015) dan Pia Liljamo (2016) menemukan bahwa tingginya beban kerja tenaga disebabkan oleh tugas-tugas tambahan diluar tugas profesional yang mereka miliki. Sementara penelitian yang dilakukan oleh Putri (2014) dan Utara (2015) menemukan bahwa tingginya beban kerja tenaga disebabkan karena unsur jumlah tenaga yang tersedia belum memadai, sehingga perlu dilakukan perekrutan tenaga baru.

\subsection{Kebutuhan Pengembangan SDM}

Hasil needs assesesment yang didapatkan melalui wawancara dan FGD dengan metode analisis kebutuhan organisasi, analisis kebutuhan pekerjaan dan analisis kebutuhan personal, didapatkan hasil kebutuhan pengembangan SDM pada Bidang Bina Marga Dinas PUPR Provinsi NTB terdiri atas peningkatan jenjang pelatihan teknis dan pelatihan manajemen administrasi. Pelatihan teknis meliputi: Pelatihan Pejabat Inti Proyek (PIP/PISK), Diklat Manajeman Proyek, Diklat Pengawasan dan Pengendalian Mutu, Diklat Konstruksi Jalan dan Jembatan, Kursus Pelatihan Pengendalian Mutu Jalan dan Jembatan, Pelatihan Peningkatan Koordinasi Perencanaan dan Program, Sertifikat Pengawasan Jalan dan Jembatan, Diklat Laboratorium Tanah, Bahan dan Beton, dan Diklat Pengawasan jalan dan Jembatan. Pelatihan manajemen administrasi terdiri dari Pelatihan Manajemen Proyek, Pelatihan Manajemen Keuangan, Pelatihan Pengadaan Barang dan Jasa, serta Pelatihan Inventaris Barang dan Jasa. Pelatihan-pelatihan tersebut dibutuhkan oleh SDM pada Bidang Bina Marga Dinas PUPR Provinsi NTB yang belum pernah mengikuti pelatihan atau yang sudah pernah mengikuti pelatihan tetapi masa berlaku sertifikatnya telah berakhir. Melakukan analisis kebutuhan pengembangan SDM sangat bermanfaat didalam membuat perencanaan pengembangan SDM agar tepat sasaran, efisien dan efektif. Seperti penelitian yang dilakukan Dzulfiqar dkk. (2016) ditemukan bahwa pelatihan diberikan untuk meningkatkan keahlian melaksanakan pekerjaan sesuai dengan tugas-tugas yang diberikan.

\section{SIMPULAN DAN REKOMENDASI}

\subsection{Simpulan}

Terdapat 3 unit kerja dan 6 kategori sumber daya manusia (SDM) pada Bidang Bina Marga Dinas PUPR Provinsi NTB yang memiliki tekanan beban kerja tinggi (rasio WISN<1). Beban kerja yang sesuai dengan jumlah ketersediaan tenaga (rasio WISN=1) ditemukan pada 1 unit kerja dan 4 kategori tenaga, sedangkan beban kerja rendah (rasio WISN $>1$ ) tidak ditemukan. Berdasarkan perhitungan beban kerja tersebut terdapat 3 unit kerja dan 11 kategori tenaga yang membutuhkan tambahan tenaga. Kebutuhan SDM Bidang Bina Marga Dinas PUPR Provinsi NTB keseluruhan sebanyak 82 orang. Saat ini Bidang Bina Marga Dinas PUPR Provinsi NTB telah memiliki 49 orang staf, jumlah kekurangan SDM sejumlah 33 orang, terdiri dari 16 orang tenaga teknis dan 17 orang 


\section{Jurnal Magister Manajemen Unram}

tenaga non teknis. Kekurangan SDM pada kategori tertentu tersebut mengakibatkan beberapa karyawan Bidang Bina Marga Dinas PUPR Provinsi NTB seringkali harus bekerja melebihi jam kerjanya karena harus menyelesaikan tugasnya dan juga untuk membantu pekerjaan unit lainnya yang seharusnya bukan menjadi tanggung jawabnya/tidak sesuai tugas pokok dan fungsinya (TUPOKSI) sehingga dapat menimbulkan konflik peran.

\subsection{Rekomendasi}

1. Setiap organisasi perlu melakukan analisis perencanaan sumber daya manusia untuk setiap unit dan kategori tenaga yang ada agar jumlah, distribusi, dan kompetensinya sesuai dengan beban kerja yang ada. Dinas PUPR Provinsi Nusa NTB dapat menggunakan metode WISN dalam menghitung beban kerja dan jumlah kebutuhan SDM serta metode needs assesement, yaitu analisis kebutuhan organisasi (organizational analysis), analisis kebutuhan pekerjaan (task/job analysis) dan analisis kebutuhan personal (person analysis) dalam menghitung kebutuhan pengembangan SDM karena metode WISN tidak hanya dapat digunakan untuk mengukur beban kerja dan menghitung kebutuhan tenaga, tetapi juga dapat digunakan untuk membuat perencanaan kebutuhan rekruitmen dengan membuat standarisasi beban kerja.

2. Berdasarkan hasil penelitian, Dinas PUPR Provinsi NTB disarankan melakukan rotasi tenaga dari unit yang kelebihan tenaga ke unit yang kekurangan SDM, melakukan kerjasama dengan perguruan tinggi yang ada di wilayah NTB dalam pelaksanaan program magang/PKL/KKN terutama saat beban puncak, serta peningkatan kompetensi SDM yang ada melalui pendidikan dan pelatihan.

3. Metode pengambilan data primer untuk mengukur beban kerja yang digunakan dalam penelitian ini adalah daily log yaitu dengan angket berupa template kegiatan, metode ini sangat bergantung dengan kerjasama dan kejujuran responden dalam mengisi angket. Penelitian selanjutnya disarankan dengan menambahkan teknik dokumentasi dalam pengisian angket agar pengukuran beban kerja yang didapatkan benar-benar sesuai dengan kondisi riil di lapangan.

\subsection{Implikasi}

\subsubsection{Implikasi teoritis}

1. Metode WISN dapat membantu organisasi untuk menganalisis kebutuhan SDM yang menyangkut jumlah maupun spesifikasi kompetensi yang dibutuhkan sehingga akan meningkatkan performance organisasi. Metode WISN dapat membantu organisasi untuk menganalisa munculnya hal-hal yang dapat mempengaruhi performance organisasi pada waktu yang akan datang.

2. Metode WISN dapat membantu organisasi untuk menganalisis kebutuhan akan pelatihan yang menjadi prioritas untuk diberikan kepada SDM yang tersedia, sehingga jika ada organisasi yang akan melakukan analisis kebutuhan pelatihan SDM dapat menggunakan metode WISN.

\subsubsection{Implikasi praktis}

1. Hasil penelitian ini dapat digunakan untuk membantu mengelola SDM pada Bidang Bina Marga Dinas PUPR Provinsi NTB berdasarkan beban kerja, jumlah kebutuhan, distribusi, jenis kompetensi dan pengembangan yang dibutuhkan tiap unit maupun kategori tenaga yang ada dengan menggunakan metode WISN untuk menghitung beban kerja dan jumlah kebutuhan SDM, serta menggunakan metode needs assesement, yaitu analisis kebutuhan organisasi (organizational analysis), analisis kebutuhan pekerjaan (task/job 


\section{Jurnal Magister Manajemen Unram}

analysis) dan analisis kebutuhan personal (person analysis) untuk menghitung kebutuhan pengembangan SDM.

2. Hasil penelitian ini dapat berkontribusi dalam peningkatan kualitas pelayanan Bidang Bina Marga Dinas PUPR Provinsi NTB melalui perencanaan SDM yang lebih baik dalam menenentukan jumlah kebutuhan SDM maupun jenis kompetensinya sesuai dengan beban kerjanya, distribusi, dan jenis pengembangan yang dibutuhkan tiap unit maupun kategori tenaga yang ada untuk dapat meningkatkan efisiensi dan efektivitas kerja karyawan dalam mencapai sasaran-sasaran kerja yang telah ditetapkann sesuai dengan tugas Bidang Bina Marga Dinas PUPR Provinsi NTB.

\section{DAFTAR PUSTAKA}

Buku:

Nazir. Mochammad. 2003, Metode Penelitian, Jakarta: Ghalia Indonesia

Shipp, Peter J. 1998. Workload indicators of staffing need (WISN) A Manual for Implementation.

Boston, USA: Initiatives Inc.

Simamora, Henry. (2006). Manajemen Sumber Daya Manusia, Edisi 2. Yogyakarta: STIE YKPN.

WHO. 2010, Workload Indicator of Staffing Need, Jeneva: WHO Press.

Jurnal :

Abideh, M. dkk., (2014), "Standard Development of Family Physicians to the Population Defined by WISN", Buletin of Environment Pharmachology and Lyfe Science. Vol.3, no.12, pp: 89-96.

Anuja Awadh, P\& Swati Chandel, (2015), "Human Resource Assessement of District Hospital Applying WISN Method: Role of Laboratory Technicians", International Journal of Medicine and Public Health, vol.3, iss. 4 pp: 267-270

Benhard, R.L.dkk, (2015), “Perencanaan Kebutuhan Sumber Daya Manusia di Puskesmas

Kabupaten Minahasa", JIKMU. Vol.5, no.1, pp: 43-53

Dharmayuda, Agung, (2014), “Analisis Beban Kerja Dokter Umum Menggunakan Metode Workload Indicators of Staffing Need (WISN) di Puskesmas Se-Kota Denpasar" , Pascasarjana Program Magister Kesehatan Masyarakat, Universitas Udayana.

Dzulfiqar Mohamad et.al, (2016), "How Productivity Can Be Affected By Human Capital",International Journal of Engineering Applied Sciences and Technology, Vol.1, ISS.6, pp: 2932.

Fitriah, dkk, (2016), “Analisis Kebutuhan Psikiater Berdasarkan Beban Kerja dengan Menggunakan Metode Workload Indicator Staffing Needs (WISN) di Unit Rawat Jalan Jiwa Rumah Sakit Ernald Bahar Provinsi Sumatera Selatan", Jurnal Kedokteran dan Kesehatan, vol.3, no.1, pp: 347-353

Hardjawinata, AH, (2006), "Analisa Kebutuhan Sumber Daya Manusia untuk Bidang Administrasi Rumah Sakit Umum Daerah Budhi Asis". Tesis Program Pasca Sarjana Kajian Administrasi Rumah Sakit Fakultas Kesehatan Masyarakat Universitas Indonesia. Jakarta.

Mile., Mekel., Karuntu, 2014, Analisis terhadap pelatihan dan pengembangan karyawan bagi peningkatan kinerja di PT. Pegadaian Gorontalo Utara, Jurnal EMBA Vol.2 No.4 Desember 2014, Hal. 167-174.

Philip Govule, dkk, (2015), "Application of Workload Indicators of Staffing Needs (WISN) in Determining Health Workerse Requirements for Mityana General Hospital, Uganda", International Journal of Public Health Research, 3(5): 254-263.

Pia Liljamo, Paivi Lavander, Pirjo Kejonen, (2016), “Determining Optimal Nursing Resources in Relation to Functions During the Qulu University Hospital Nurse Staffing Management Project", IMIA and IOS Press, 658,3-3. 


\section{Jurnal Magister Manajemen Unram Vol. 7, No 2. Juni 2018 \\ NATIONALY ACCREDITED JOURNAL - DECREE NO. 21/E/KPT/2018}

Putri Julia. dkk, (2014), “Analisis Kebutuhan Tenaga Perawat Berdasarkan Beban Kerja dengan Menggunakan Metode Workload Indicator Staff Need (WISN) dan Work Sampling", Jurnal Teknik Industri USU, vol.5, no.2, pp:22-25.

Saikat Das, dkk.l, (2013), "A Study to Calculate the Nursing Staff Requirements for The Maternity Ward of Medical College Hospital, Kolkata Applying WISN Method". IOSR Journal of Dental and Medical Sciences. Vol.8, iss.3, pp: 01-07.

Satish, S. dkk, (2015), "Gap Analysis in Staffing Using Workload Indicators of Staffing Need Method in Tertiary Care Teaching Hospital", International Journal of Scientific Research, vol.4, iss: 7, pp: 376377

Utara Hartawan. I.G.A Gede, (2016), “ Analisis Kebutuhan Perawat Berdasarkan Pengamatan Terhadap Penanganan Pasien Dewasa dan Anak-Anak di Unit Gawat Darurat Rumah Sakit Bali Royal", Online Jurnal Universitas Udayana, vol.47, no.2, pp:116-125

Wicaksono. 2016, Pengaruh pelatihan dan pengembangan sumber daya manusia dalam rangka meningkatkan semangat kerja dan kinerja karyawan (Studi di SKM Unit V PT. Gudang Garam, Tbk Kediri). Jurnal Bisnis dan Manajemen Vol. 3 No.1, Januari 2016.

2004, Keputusan Menteri Kesehatan Republik Indonesia Nomor: 81/Menkes/SK/2004

tentang Pedoman Penyusunan Perencanaan SDM Kesehatan di Tingkat Propinsi, Kab/Kota serta Rumah Sakit. Jakarta : Departemen Kesehatan R.I. 